\title{
Research Article \\ Effects of Titanium Micro-Nanopermeable Structures on Osteogenic Differentiation
}

\author{
Jiannan Liu, ${ }^{1}$ Mingjiang Jin, ${ }^{2}$ Zhen Zhang, ${ }^{1}$ Lihuang $W u,{ }^{2}$ Xuejun Jin $\left(\mathbb{D},{ }^{2}\right.$ \\ Chenping Zhang $\mathbb{D}^{1}{ }^{1}$ and Yue Xing ${ }^{3}$ \\ ${ }^{1}$ Department of Oral Maxillofacial-head and Neck Oncology, Ninth People's Hospital, Shanghai Jiao Tong University School \\ of Medicine, Shanghai 200011, China \\ ${ }^{2}$ Institute of Phase Transformation and Complex Structure, School of Materials Science and Engineering, Shanghai Jiao \\ Tong University, Shanghai 200240, China \\ ${ }^{3}$ Department of Ophthalmology, Ninth People's Hospital, Shanghai Jiao Tong University School of Medicine, Shanghai 200011, China
}

Correspondence should be addressed to Xuejun Jin; jin@sjtu.edu.cn and Chenping Zhang; zhang.chenping@hotmail.com

Received 8 April 2018; Revised 16 July 2018; Accepted 14 August 2018; Published 17 December 2018

Academic Editor: Martin Andersson

Copyright (c) 2018 Jiannan Liu et al. This is an open access article distributed under the Creative Commons Attribution License, which permits unrestricted use, distribution, and reproduction in any medium, provided the original work is properly cited.

To evaluate the effects of different Ti surface micro-nanopermeable structures on osteoblast proliferation and differentiation and explore related mechanisms, hybrid technology of sandblast, acid etching, and hydrothermal (HT) was used to form the micronanopermeable surface of Ti. Scanning electron microscopy (SEM), surface profiler, and contact angle meter were utilized to assess the surface morphology, roughness, and hydrophilicity. MTT, SEM, alkaline phosphatase (ALP) activity assay, and realtime PCR were performed to investigate proliferation, adhesion and spreading, and differentiation of MC3T3-E1 cells grown on polished Ti (control), sandblast + acid etching- (SLA-) treated Ti, and SLA + HT-treated Ti. MAPK signal pathway activity was evaluated by Western blotting. The results showed that SLA + HT could result in not only formation of microscale groove containing submicroscale and nanoscale porous structures in Ti samples but also rough and hydrophilic surface. SLA + HT treatment has the best effects on cell adhesion and spreading. Significantly increased levels of ALP activity and osteogenic genes including Alp, Ocn, Opn, Runx2, and Bsp, as well as p38 but not ERK phosphorylation, were found in the SLA + HT group. In conclusion, sandblast, acid etching, and hydrothermal treatment on Ti regulates osteoblast differentiation, while activation of the MAPK p38 signaling pathway served as the mechanism.

\section{Introduction}

Osseointegrated implants have been used to replace missing teeth, maxillofacial, or orthodontic anchorage for many years. The advantage of these implants as orthodontic anchorage is that the implant is absolutely immobile because of the absence of periodontal ligament [1]. The use of titanium (Ti) and its alloys as implant materials is considered to be a suitable treatment option for patients with prosthetic reconstruction in fully edentulous patients in order to increase masticatory function [2]. It is reported that surface microstructure of suspensions and pockets of $\mathrm{Ti}$ implants could affect the cell spreading, morphology, and its alignment [3]. Moreover, surface roughness and surface chemistry (Ti hydride) of $\mathrm{Ti}$ implant are considered to play a critical role on its biocompatibility $[3,4]$. The benefits of micro-nanotextured implant surface have been proved using multiscale analytical techniques to study the boneimplant interface at sufficient resolution $[5,6]$. Therefore, effective improvement of the physical and chemical properties of Ti implants will be helpful for achieving faster osseointegration [7].

Sandblasted/acid etched (SLA) surface, a well-established method for ablative roughening of implant surfaces, is a complex submicron surface with microcavities of 20 to $40 \mu \mathrm{m}$ diameter produced by mechanical modification and micropits of 0.5 to $3 \mu \mathrm{m}$ diameter produced by acid etching [8]. Many studies have shown that these surface could not only increase impact of modifications on osteogenic cell adhesion, spreading, gene expression, and cytokine release in vitro 
$[9,10]$ but also increase bone-to-implant contact (BIC) and removal torque forces in vivo [11]. Additionally, studies have suggested that in comparison with conventional SLA implants, modified SLA (MSLA) implants yielded more successful bone formation at the initial stage of healing, resulting in significantly higher levels of bone-to-implant contact [12-15]. Hydrothermal method, one of the surface treatment methods with the features of simpleness and effectiveness, has been employed for Ti implant surface modification [16]. Recently, hydrothermal treatment, as a simple and effective surface treatment method with the ability to diminish metal ion release, has been employed for improving the in vitro biocompatibility and bone formation on Ti implants [17]. However, the effects of hydrothermal treatment on SLA implants in the setting of osteodifferentiation have not been investigated yet.

In this study, hybrid technology of sandblast, acid etching, and hydrothermal (HT) were used to form the micronanopermeable surface of $\mathrm{Ti}$, and the effects of these Ti material on osseointegration were achieved by using MC3T3-E1 osteoblast cell line proliferation, adhesion, spreading, and differentiation model.

\section{Materials and Methods}

2.1. Sample Preparation. Ti discs with $10 \mathrm{~mm}$ diameter and $1.5 \mathrm{~mm}$ thickness were prepared using commercial Ti rod (TA2) with a diameter of $10 \mathrm{~mm}$ and used as the substrate material. The Ti substrates were firstly polished by sandpaper (grades $160,600,1200$, and 2000 ) sequentially on polishing plates $(1 \mu \mathrm{m}$ or $6 \mu \mathrm{m})$ to obtain the smooth surface with natively formed oxide film (denoted as polished $\mathrm{Ti}$ ). The smooth Ti surface was sandblasted with $400 \mu \mathrm{m} \mathrm{SiO}_{2}$ spheres at a pressure of $0.5 \mathrm{MPa}$ and etched in $\mathrm{HCl}$ $(5.8 \mathrm{~mol} / \mathrm{L})+\mathrm{H}_{2} \mathrm{SO}_{4}$ solution $(8.96 \mathrm{~mol} / \mathrm{L})$ for $30 \mathrm{~min}$ at $80^{\circ} \mathrm{C}$ to form the microstructured surface and then ultrasonically cleaned with acetone, ethanol, and ultrapure water successively to obtain the SLA Ti sample. The SLA + HT Ti samples were prepared based on the SLA Ti sample by the alkali-hydrothermal reaction. A typical preparation process was as follows: SLA Ti sample was immersed in $20 \mathrm{~mL}$ of $5 \mathrm{M} \mathrm{NaOH}$ aqueous solution, followed by hydrothermal treatment at $80^{\circ} \mathrm{C}$ for $4 \mathrm{~h}$ or $8 \mathrm{~h}$ at normal pressure. The as-prepared thin films were then rinsed repeatedly with ultrapure water until the $\mathrm{pH}$ of water dropped to 7 to obtain the SLA + HT Ti samples.

2.2. Surface Characterization. Surface morphology of the obtained samples was examined by scanning electron microscopy (SEM, Hitachi S-4800). An optical profilometer (Contour GT, Veeco) was used to assess the surface roughness of the samples, and the contact angle between the sample surface and deionized water was used to evaluate the hydrophilicity of samples. The contact angle was measured by a contact angle meter at $25^{\circ} \mathrm{C}$.

2.3. Cell Culture and Grouping. MC3T3-E1 cells were purchased from the American Type Cell Culture Collection (ATCC, Manassas, VA, USA) and cultured at $37^{\circ} \mathrm{C}$ in alpha- minimum essential medium (Invitrogen-Gibco, Carlsbad, CA, USA) supplemented with 10\% fetal bovine serum (FBS). Grouping: control group: MC3T3-E1 grown on polished Ti samples; SLA: MC3T3-E1 grown on SLA Ti $(400 \mu \mathrm{m} \mathrm{SiO}$ sandblast + acid etching) samples; SLA + HT: MC3T3-E1 grown on SLA + HT $\left(400 \mu \mathrm{m} \mathrm{SiO}_{2}\right.$ sandblast + acid etching + $4 \mathrm{~mol} / \mathrm{L} \mathrm{NaOH}$ hydrothermal for $4 \mathrm{~h}$ ) samples.

2.4. Cell Proliferation. MC3T3-E1 cells $(3 \times 103$ cells $)$ were seeded in 24-well plates containing the above Ti disc samples including polished $\mathrm{Ti}$, SLA-treated $\mathrm{Ti}$, and SLA + HT-treated $\mathrm{Ti}$ in complete growth medium (alpha-minimum essential medium $+10 \%$ FBS). One, four, and seven days later, cell proliferation was evaluated by MTT assay following the manufacturer's instructions and using a microplate reader (Molecular Devices, Sunnyvale, CA, USA) to measure the absorbance. All experiments were performed at least 3 times, each time in triplicate.

2.5. Cell Adhesion. MC3T3-E1 cells $(3 \times 104$ cells) were seeded in 24-well plates containing the above Ti disc samples including polished Ti, SLA-treated Ti, and SLA + HT-treated $\mathrm{Ti}$ in complete growth medium (alpha-minimum essential medium $+10 \%$ FBS). Two and 24 hours later, cells were rinsed by PBS for 3 times after medium aspiration and fixed in $2.5 \%$ glutaraldehyde in $0.1 \mathrm{M}$ cacodylate at $4^{\circ} \mathrm{C}$ overnight. The surfaces were then dehydrated using a series of graded alcohols (70\%, 90\%, 95\%, 98\%, and 100\% ethanol), washed with hexamethyldisilazane, and placed in a desiccator overnight. Specimens were mounted in aluminum stubs, goldcoated, and observed under a SEM. All experiments were performed at least 3 times, each time in triplicate.

2.6. Alkaline Phosphatase (ALP) Evaluation. MC3T3-E1 cells $(3 \times 104$ cells $)$ were seeded in 24 -well plates containing the above Ti disc samples including polished Ti, SLA-treated $\mathrm{Ti}$, and SLA + HT-treated $\mathrm{Ti}$ in complete growth medium and osteogenic differentiation medium (LonzaCo. Ltd., CA, USA). Change was performed after achieving of cell adhesion onto the Ti surface. One and four days later, ALP activity was evaluated by using an Alkaline Phosphatase Colorimetric Assay Kit (Abcam, Cambridge, UK) according to the manufacturer's instructions, while ALP staining was evaluated by a BCIP/NBT kit from ZSBIO Co. Ltd. from Beijing, China. All experiments were performed at least 3 times, each time in triplicate.

2.7. Quantitative Real-Time Reverse Transcription Polymerase Chain Reaction (qRT-PCR) Assay of Osteogenic Genes. Total cellular RNA was extracted from cells collected from different Ti surfaces at days 4,7 , and 14 as described above (including polished $\mathrm{Ti}$, SLA-treated $\mathrm{Ti}$, and SLA+HTtreated $\mathrm{Ti}$ ) with TRIzol reagent (Invitrogen). RT-PCR was carried out using a One Step SYBR ${ }^{\circledR}$ PrimeScript ${ }^{\mathrm{TM}}$ RTPCR kit (Takara, Dalian, China) and an iQ5 Real-time PCR Detection system (Bio-Rad, Hercules, CA, USA). Expression of the glyceraldehyde 3-phosphate dehydrogenase (GAPDH) gene was assayed simultaneously with samples as an internal control. Relative gene expression was determined by the $2-\Delta \Delta \mathrm{CT}$ method [18]. Oligonucleotide 
TABle 1: Primer sequences.

\begin{tabular}{lcc}
\hline Gene name & Forward primer $\left(5^{\prime}-3^{\prime}\right)$ & Reverse primer $\left(5^{\prime}-3^{\prime}\right)$ \\
\hline Alp & CTGCCTGAAACAGAAAGTCTGC & TATGTCTTTACCAGGAGGCGTG \\
Ocn & TGAGGACCATCTTTCTGCTCAC & CTATGGAAGGCTAAGGGCTCTG \\
Opn & TTCTCCTGGCTGAATTCTGAGG & GCTGCCAGAATCAGTCACTTTC \\
Runx2 & ACGAAAAATTAACGCCAGTCGG & CACTTCACCCTCAGGACCG \\
Bsp & GGCTATTGATCAAGCAGCACAC & GGGGTGTGATAAAGGAACGTCA \\
Gapdh & GTCCCAGCTTAGGTTCATCAGG & ATGGCAACAATCTCCACTTTGC \\
\hline
\end{tabular}

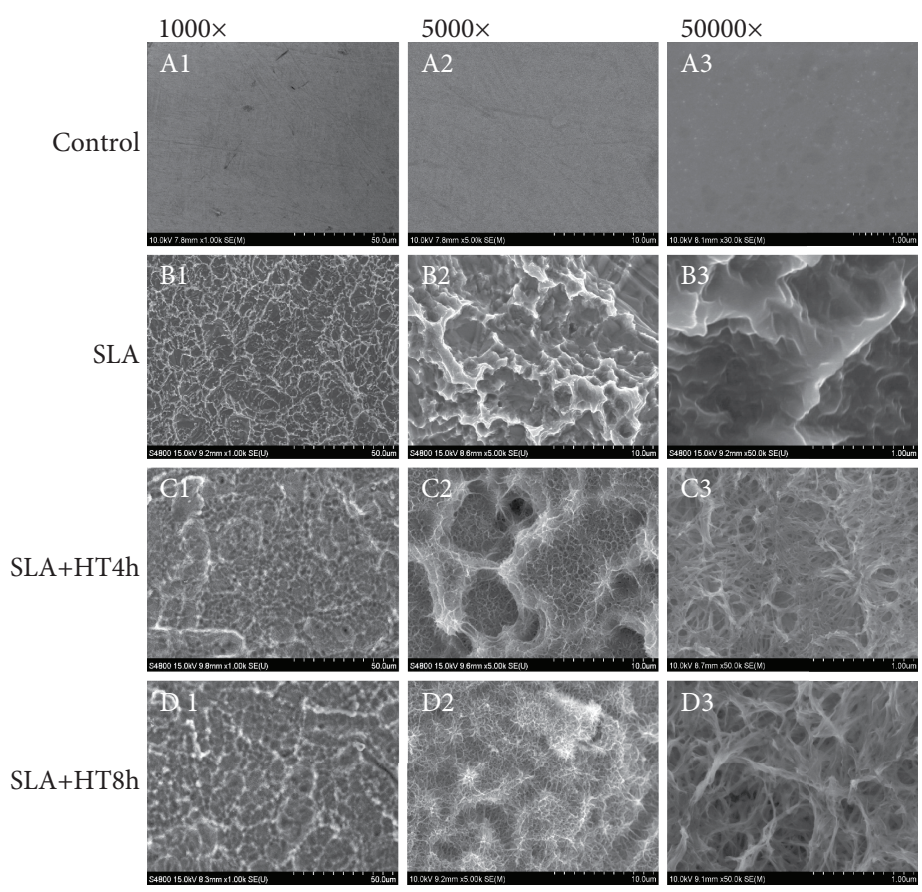

FIgure 1: Surface morphology of the polished $\mathrm{Ti}$ and $\mathrm{Ti}$ with different surface modification. Control: polished Ti; SLA: $400 \mu \mathrm{m}$ SiO 2 sandblast + acid etching; SLA + HT4h: $400 \mu \mathrm{m} \mathrm{SiO}{ }_{2}$ sandblast + acid etching + $4 \mathrm{~mol} / \mathrm{L} \mathrm{NaOH}$ hydrothermal for $4 \mathrm{~h}$; SLA + HT8h: $400 \mu \mathrm{m}$ $\mathrm{SiO}_{2}$ sandblast + acid etching $+4 \mathrm{~mol} / \mathrm{L} \mathrm{NaOH}$ hydrothermal for $8 \mathrm{~h}$. 1 represents $1000 \mathrm{x}$ magnification; 2 represents 5000x magnification; 3 represents 50000x magnification.

primers specific for alkaline phosphatase (Alp), osteocalcin (Ocn), osteopontin (Opn), runt-related transcription factor 2 (Runx2), bone sialoprotein (Bsp), and GAPDH are listed in Table 1. All experiments were performed at least 3 times, each time in triplicate.

2.8. Western Blotting. Cells collected at days 1 and 4 from different Ti surfaces as described above (including polished $\mathrm{Ti}$, SLA-treated $\mathrm{Ti}$, and SLA + HT-treated Ti) were lysed in RIPA buffer, followed by high-speed centrifugation and protein quantification using a bicinchoninic acid assay. Cellular proteins were separated by sodium dodecyl sulfatepolyacrylamide gel electrophoresis and transferred to polyvinylidene difluoride membranes. After blocking, the membranes were incubated with primary monoclonal antibodies against p38, phosphorylated p38, extracellular signal-regulated kinase $1 / 2$ signaling cascade (ERK1/2), and phosphorylated ERK1/2 (Cell Signaling Technology, Cambridge, MA, USA). GAPDH (Santa Cruz Biotechnology, Santa Cruz, CA, USA) was used as the loading control. Horseradish peroxidase-conjugated secondary antibodies were applied to detect labeled proteins. Protein bands were developed with SuperSignal Ultra Chemiluminescent Substrate (Pierce, Rockford, IL, USA) on X-ray films (Kodak, Tokyo, Japan). All experiments were performed at least 3 times, each time in triplicate.

2.9. Statistical Analysis. Statistical analysis was carried out using SPSS v18 (SPSS, Chicago, IL, USA). Data were reported as means \pm standard deviation (SD). One-way analysis of variance (ANOVA) was used to determine the significance of difference between groups. Multiple comparison using Bonferroni/Tukey test was used following ANOVA. A $p$ value $<0.05$ was considered significant.

\section{Results}

\subsection{Surface Characteristics of Different Ti Samples}

3.1.1. Morphology. The surface morphologies of the polished $\mathrm{Ti}$, SLA Ti, and SLA $+\mathrm{HT} \mathrm{Ti}(4 \mathrm{~h}$ and $8 \mathrm{~h})$ are presented 
TABLE 2: Roughness of titanium surface with different surface modification.

\begin{tabular}{lcccc}
\hline Groups & $\mathrm{Ra} / \mu \mathrm{m}$ & $\mathrm{Rq} / \mu \mathrm{m}$ & $\mathrm{Rp} / \mu \mathrm{m}$ & 0.191 \\
Control & 0.075 & 0.091 & 0.450 & 0.254 \\
SLA & 0.172 & 0.214 & 12.600 & 0.502 \\
SLA + HT4h & 5.010 & 5.840 & 0.575 & 12.100 \\
SLA + HT8h & 0.163 & 0.216 & 0.786 \\
\hline
\end{tabular}

$\mathrm{Ra}$ is the arithmetical average roughness; $\mathrm{Rq}$ is the root mean square roughness; $\mathrm{Rp}$ is the maximum peak roughness; $\mathrm{Rv}$ is the maximum valley roughness.

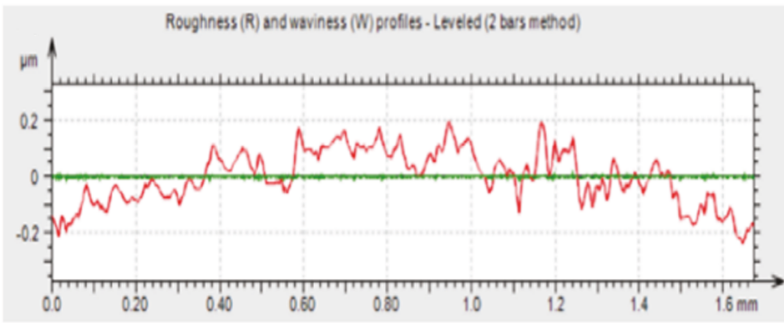

(a)

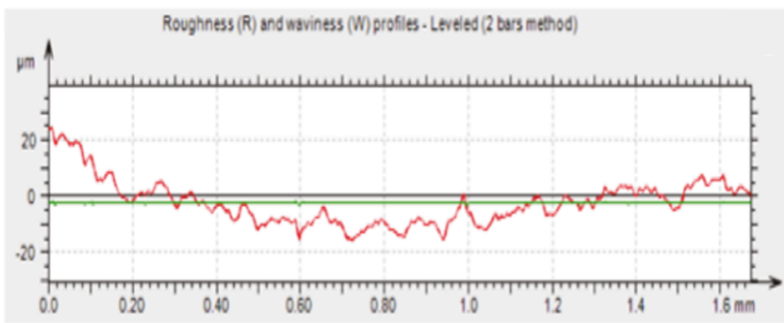

(c)

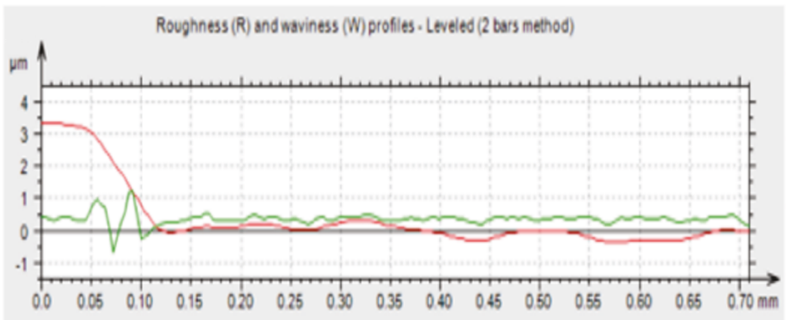

(b)

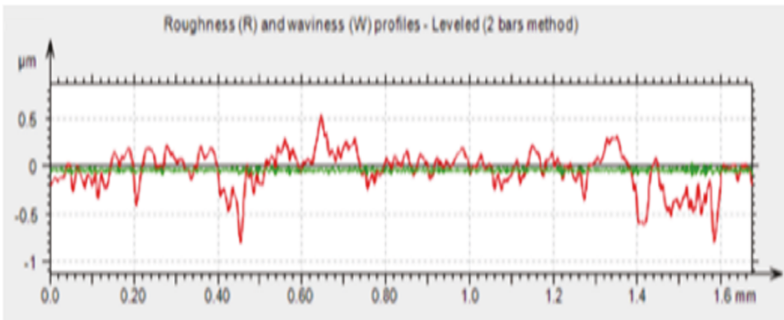

(d)

FIgure 2: Surface roughness of polished $\mathrm{Ti}$ and $\mathrm{Ti}$ with different surface modification. (a) Control: polished $\mathrm{Ti}$; (b) SLA: $400 \mu \mathrm{m}$ SiO 2 sandblast + acid etching; (c) SLA + HT4h: $400 \mu \mathrm{m} \mathrm{SiO} 2$ sandblast + acid etching + $4 \mathrm{~mol} / \mathrm{L} \mathrm{NaOH}$ hydrothermal for $4 \mathrm{~h}$; (d) SLA + HT8h: $400 \mu \mathrm{m} \mathrm{SiO}{ }_{2}$ sandblast + acid etching $+4 \mathrm{~mol} / \mathrm{L} \mathrm{NaOH}$ hydrothermal for $8 \mathrm{~h}$.

in Figure 1. The polished Ti surface was relatively smooth (Figure 1(a)). After surface treatment by $\mathrm{SiO}_{2}$ sandblasting and subsequent acid etching, $10-30 \mu \mathrm{m}$ size microscale structure units and limited amount of micro-nanostructures could be observed on the Ti surface (Figures 1(b1)-1(b3)). These $10-30 \mu \mathrm{m}$ size microscale structure units and micronanostructures were also displayed on SLA + HT4h Ti samples, and microscale groove containing submicroscale and nanoscale porous structures could be found under high magnification $(50000 \mathrm{x})$ (Figures $1(\mathrm{c} 1)-1(\mathrm{c} 3))$. However, destroyed surface micro-nanostructures and porous structures could be observed in SLA + HT8h Ti samples (Figures $1(\mathrm{~d} 1)-1(\mathrm{~d} 3)$ ).

3.1.2. Roughness and Hydrophilicity. We further evaluated the surface roughness and hydrophilicity of the above materials, and results are shown in Table 2 and Figures 2 and 3. It can be seen that the surface roughness $(\mathrm{Ra})$ of the polished Ti, SLA Ti, SLA + HT4h Ti, and SLA + HT8h Ti surfaces was, respectively, $0.075 \pm 0.004 \mu \mathrm{m}, 0.172 \pm 0.008 \mu \mathrm{m}, 5.010$ $\pm 0.250 \mu \mathrm{m}$, and $0.163 \pm 0.008 \mu \mathrm{m}$, and the corresponding water contact angle of the polished Ti, SLA Ti, SLA+ HT4h Ti, and SLA + HT8h Ti surfaces was, respectively, $88.8 \pm 1.44^{\circ}, 53.0 \pm 4.13^{\circ}, 0 \pm 0^{\circ}$, and $18.8 \pm 1.90^{\circ}$, indicating the highest surface roughness and hydrophilicity of the $\mathrm{SLA}+\mathrm{HT} 4 \mathrm{~h} \mathrm{Ti}$. Since the roughness of SLA $+\mathrm{HT} 4 \mathrm{~h} \mathrm{Ti}$ was significantly higher than that of the polished $\mathrm{Ti}$ and the water contact angle decreased, it suggested that the surface modification procedure apparently changed the initial smooth and hydrophobic surface to rough and hydrophilic surface.

\subsection{Osteoblast Proliferation, Adhesion, and Spreading Pattern on Ti Surface with Different Modification}

3.2.1. Proliferation. After surface characteristic evaluation of the different Ti samples, we further testify the effects of different Ti samples on osteoblast behavior. According to the cell proliferation results by MTT assay, although slightly higher cell proliferation was found on the control group compared to that of the SLA group and the SLA + HT group, no significant difference was found on the cell proliferation among these three groups at days 1, 4, and 7 (all $p>0.05$ ) (Figure 4). These results indicated no effects on cell proliferation of $\mathrm{Ti}$ surface with different modification.

3.2.2. Adhesion and Spreading. Cell adhesion and spreading were evaluated by SEM. At the time $2 \mathrm{~h}$, only a few cells with round shape could be found in the control group, whereas 


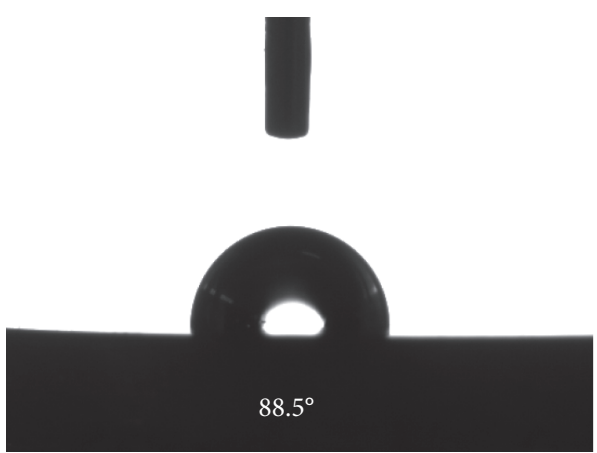

(a)

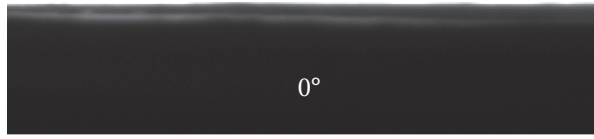

(c)

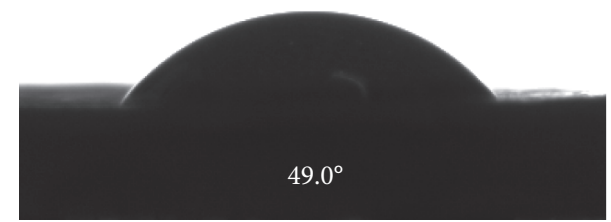

(b)
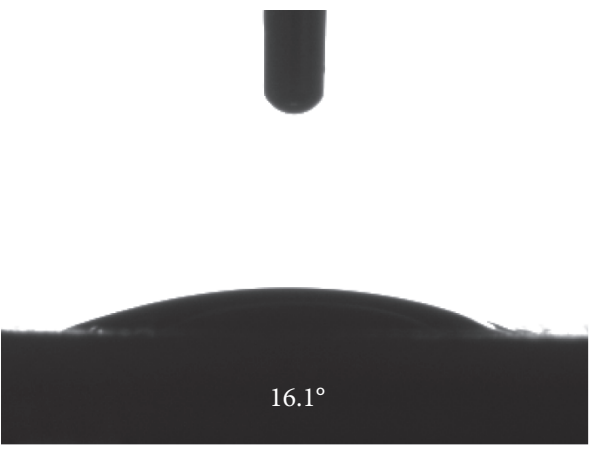

(d)

FIgure 3: Surface hydrophilicity of polished $\mathrm{Ti}$ and $\mathrm{Ti}$ with different surface modification. (a) Control: polished $\mathrm{Ti}$; (b) SLA: $400 \mu \mathrm{m} \mathrm{SiO}{ }_{2}$ sandblast + acid etching; (c) SLA + HT4h: $400 \mu \mathrm{m} \mathrm{SiO}$, sandblast + acid etching + $4 \mathrm{~mol} / \mathrm{L} \mathrm{NaOH}$ hydrothermal for $4 \mathrm{~h}$; (d) SLA + HT8h: $400 \mu \mathrm{m} \mathrm{SiO}{ }_{2}$ sandblast + acid etching $+4 \mathrm{~mol} / \mathrm{L} \mathrm{NaOH}$ hydrothermal for $8 \mathrm{~h}$.

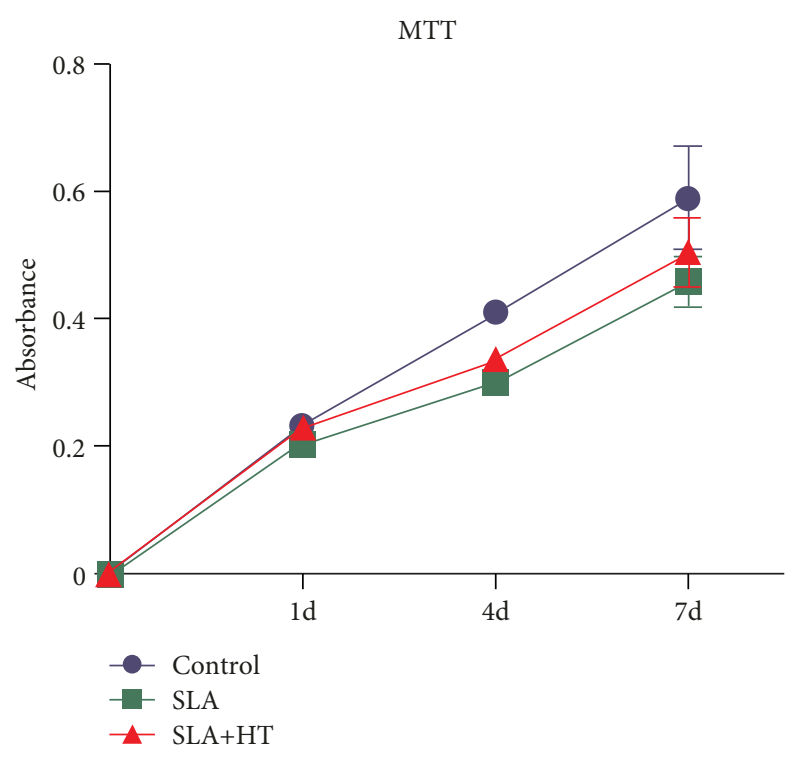

FIGURE 4: Cell proliferation analysis of osteoblasts on Ti materials with different surface modification. No difference was found on the cell proliferation when seeding on polished $\mathrm{Ti}$, Ti with SLA treatment, and $\mathrm{Ti}$ with SLA + HT treatment. SLA: $400 \mu \mathrm{m} \mathrm{SiO}_{2}$ sandblast + acid etching; SLA + HT: $400 \mu \mathrm{m} \mathrm{SiO}{ }_{2}$ sandblast + acid etching $+4 \mathrm{~mol} / \mathrm{L} \mathrm{NaOH}$ hydrothermal for $4 \mathrm{~h}$. more attached cells with fully extended shape, typical fibroblast morphology, bipolar changes, and increased amount of filopodia and plateopodia could be found in the SLA and SLA + HT groups (Figure 5(a)). At $24 \mathrm{~h}$ time point, more cells with fully extended shape could be found in the control group, whereas significant adhesion with pieces connected cells showing typical fibroblast morphology, bipolar changes, and a large amount of filopodia and plateopodia could be found in the SLA and SLA + HT groups (Figure 5(b)). These results indicated increased cell spreading on the Ti surface with SLA and SLA + HT modification, especially with the SLA + HT modification.

\subsection{Osteoblast Differentiation Pattern on Ti Surface with Different Modification}

3.3.1. ALP Activity. Successful osseointegration requires osteoblast differentiation de novo. Since the effects on osteoblast adhesion and spreading were observed above, we further evaluated the effects of different Ti surfaces on osteoblast differentiation. Of the 3 groups, osteoblasts in the SLA + HT group exhibited the highest ALP activity on day 1 and day 4, which was significantly higher than those in the SLA and control groups at corresponding time points (Figure 6(a)). ALP staining was consistent with those observed in the ALP activity (Figure 6(b)). These results indicated increased cell differentiation on the Ti surface with SLA and SLA + HT modification, especially with the SLA + HT modification. 

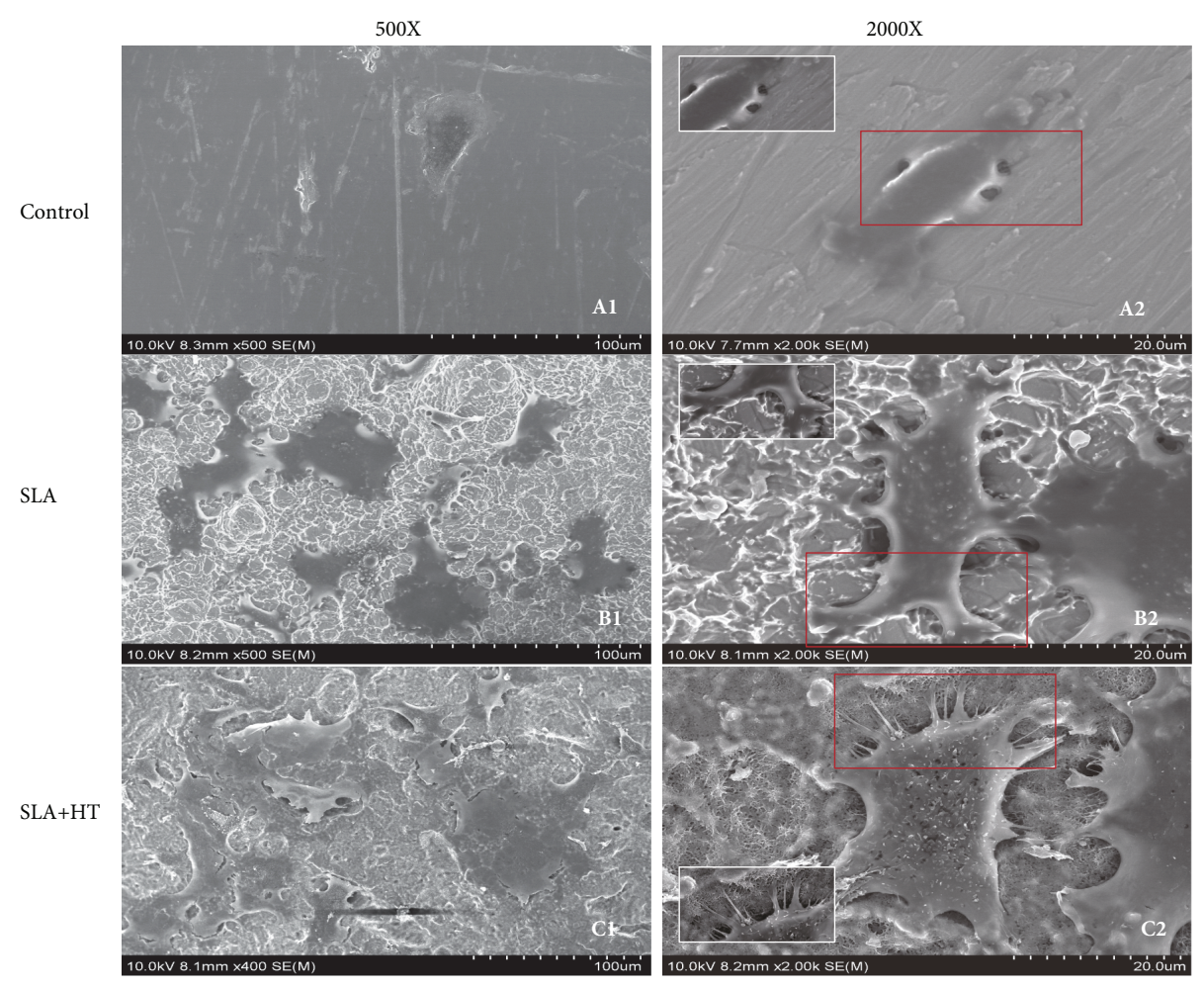

(a)
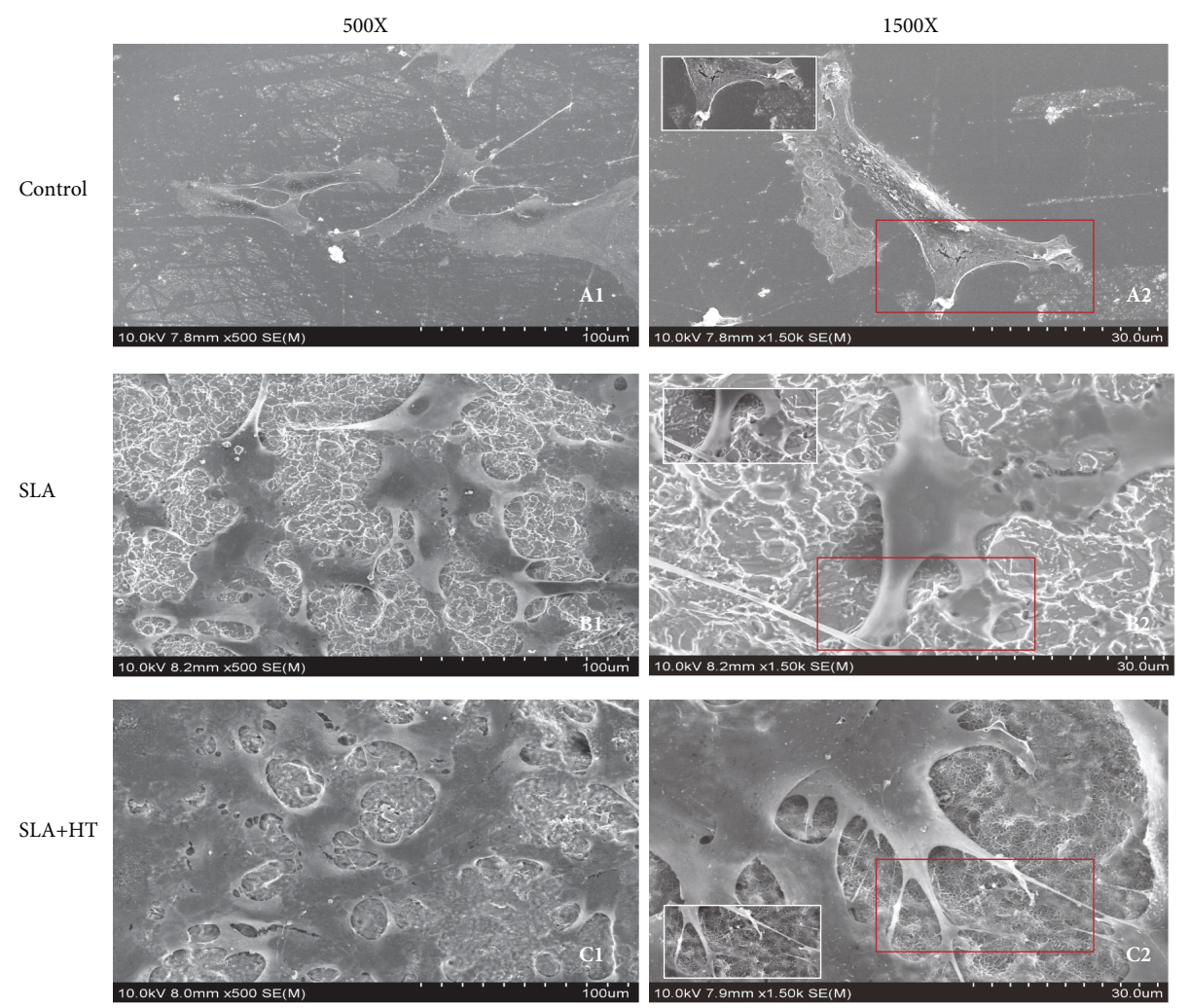

(b)

FIGURE 5: Cell adhesion and spreading of osteoblasts after $2 \mathrm{~h} \mathrm{(a)} \mathrm{and} 24 \mathrm{~h}$ (b) on Ti materials with different surface modification. Control: polished Ti; SLA: $400 \mu \mathrm{m} \mathrm{SiO}{ }_{2}$ sandblast + acid etching; SLA + HT: $400 \mu \mathrm{m} \mathrm{SiO} 2$ sandblast + acid etching $+4 \mathrm{~mol} / \mathrm{L} \mathrm{NaOH}$ hydrothermal for $4 \mathrm{~h}$. 


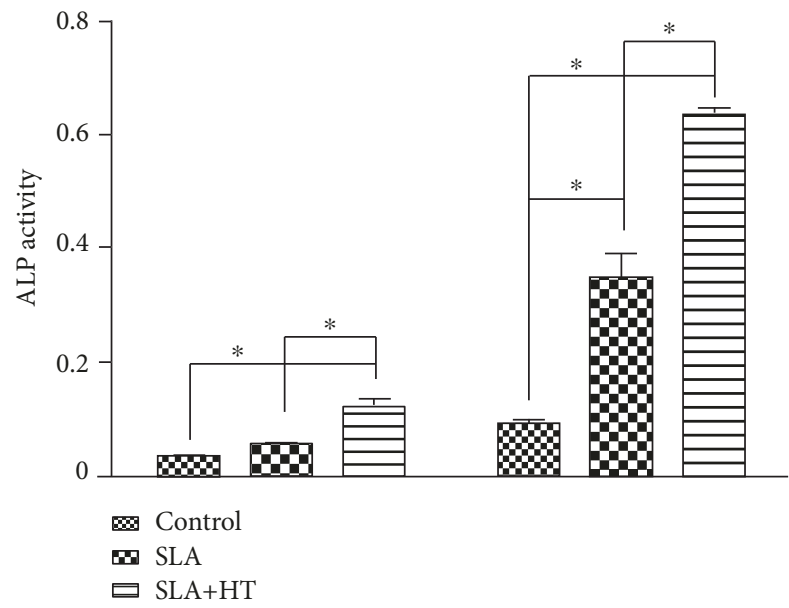

(a)

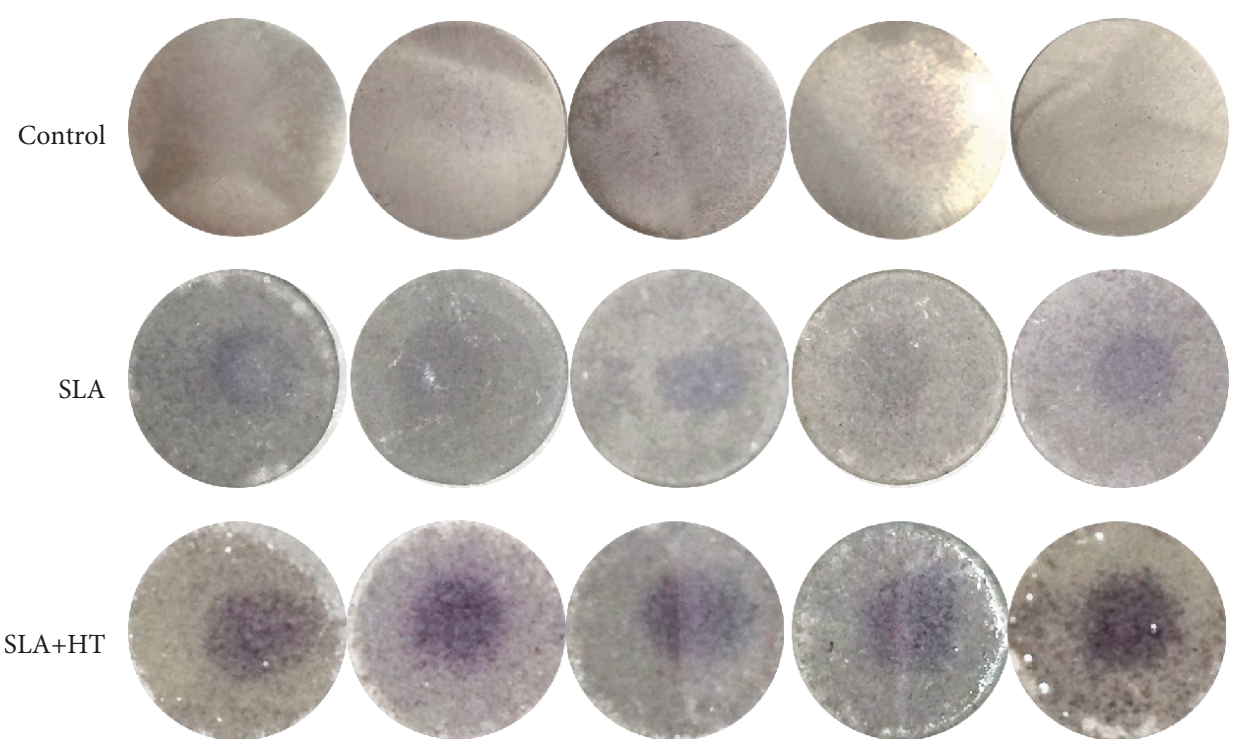

(b)

FIGURE 6: Alkaline phosphatase (ALP) activity and staining of osteoblasts after on Ti materials with different surface modification. (a) Quantification of ALP activity; (b) ALP staining at day 4. Control: polished Ti; SLA: $400 \mu \mathrm{m} \mathrm{SiO}_{2}$ sandblast + acid etching; SLA + HT: $400 \mu \mathrm{m} \mathrm{SiO}{ }_{2}$ sandblast + acid etching $+4 \mathrm{~mol} / \mathrm{L} \mathrm{NaOH}$ hydrothermal for $4 \mathrm{~h} .{ }^{*} p<0.05$.

3.3.2. Osteogenic Gene Expression. We also evaluated the osteogenic related genes in these cells grown on different $\mathrm{Ti}$ samples; the results showed that the highest Alp on day 4, Ocn on day 7 and day 14, Opn on day 7 and day 14, Runx2 on days 4,7 , and 14, and Bsp on days 4,7 , and 14 were found in the SLA + HT group compared to those of the SLA group and control group (Figure 7). These results were consistent with the results of the ALP activity.

3.4. MAPK p38 Signaling Was Involved in the Osteoblast Differentiation on SLA +HT-Treated Ti Surface. According to previous description, p38 MAPK and ERK MAPK signaling was involved in the osteoblast behavior on the Ti surface; we therefore further explored the related mechanisms in the osteoblast differentiation observed above. The results showed increased p38 phosphorylation with incubation time, and significantly increased p 38 phosphorylation could be found on Ti with SLA + HT treatment compared to that with control and SLA treatment (Figures 8(a) and 8(b)). Moreover, no ERK phosphorylation was detected from osteoblasts grown on the Ti materials with different treatments (Figure 8(c)).

\section{Discussion}

Dental implants modified through sandblasting and acid etching are quite common at the commercial level and have been evaluated in clinical trials. These surface techniques, frequently used in the biomedical market, produce high levels of surface roughness [19]. These implants with macroroughness and microtopographic features have a survival success rate of $98.8 \%$ for up to 10 years [20]. In the present study, we firstly employed hybrid technology of sandblast, acid etching, and hydrothermal (HT) to form the micro-nanopermeable 

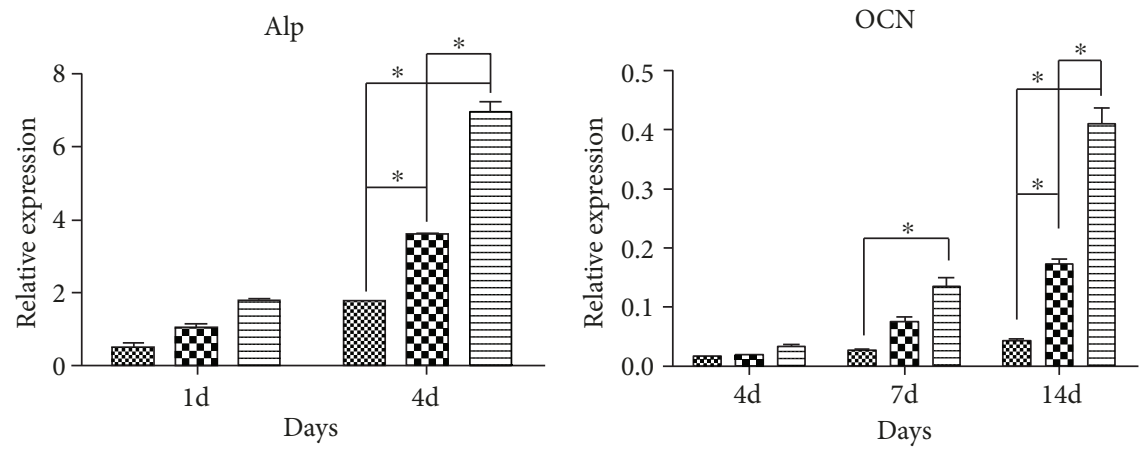

$\otimes$ Control

m SLA

$\Xi \mathrm{SLA}+\mathrm{HT}$

$\otimes$ Control

SLA

$\boxminus$ SLA+HT

(a)

(b)
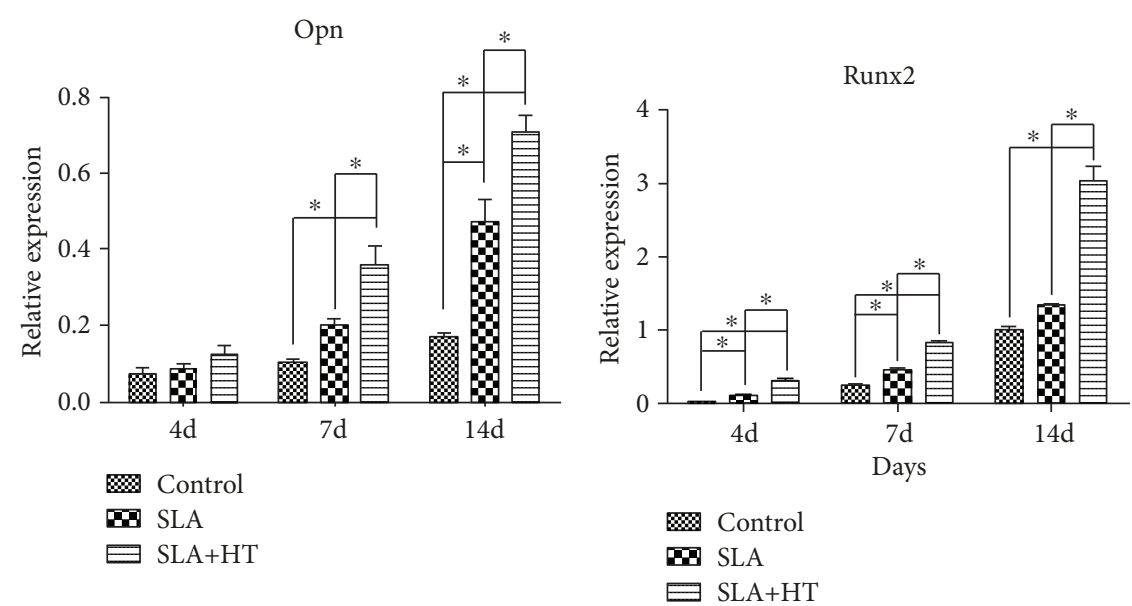

(c)

(d)

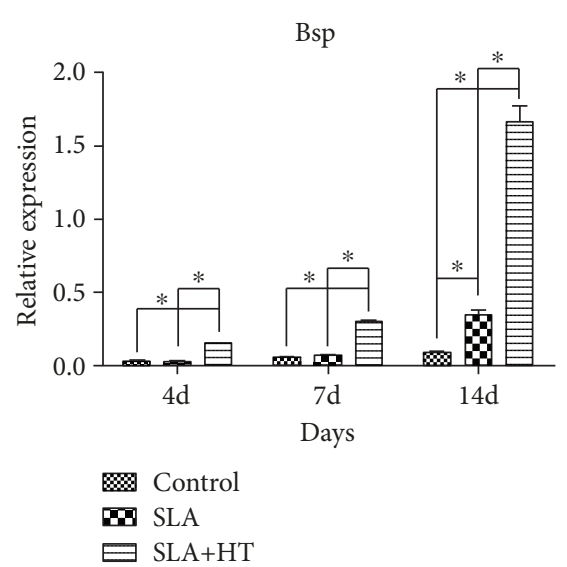

(e)

Figure 7: Quantitative PCR of osteogenic related gene expression of osteoblasts after on Ti materials with different surface modification. (a) Alkaline phosphatase (Alp); (b) osteocalcin (Ocn); (c) osteopontin (Opn); (d) runt-related transcription factor 2 (Runx2); (e) bone sialoprotein (Bsp). Control: polished Ti; SLA: $400 \mu \mathrm{m} \mathrm{SiO} 2$ sandblast + acid etching; SLA + HT: $400 \mu \mathrm{m} \mathrm{SiO2} \mathrm{sandblast+acid} \mathrm{etching}$ $+4 \mathrm{~mol} / \mathrm{L} \mathrm{NaOH}$ hydrothermal for $4 \mathrm{~h} .{ }^{*} p<0.05$.

surface of Ti and then performed surface characteristic evaluation by using SEM, surface profiler, and contact angle meter, followed by osteogenic differentiation evaluation by using MC3T3-E1 osteoblast cell line proliferation, adhesion, spreading, and differentiation model. Our results demonstrated that the formation of microscale groove containing 


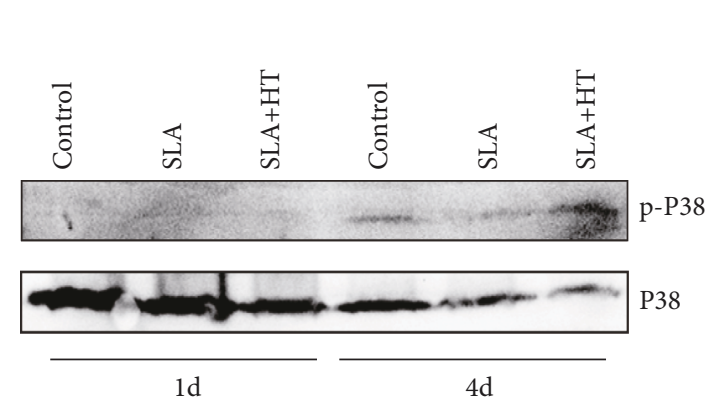

(a)

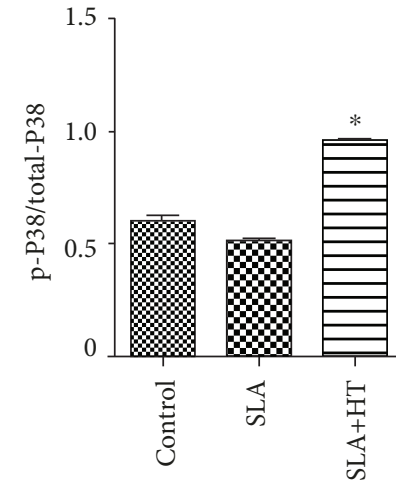

(b)

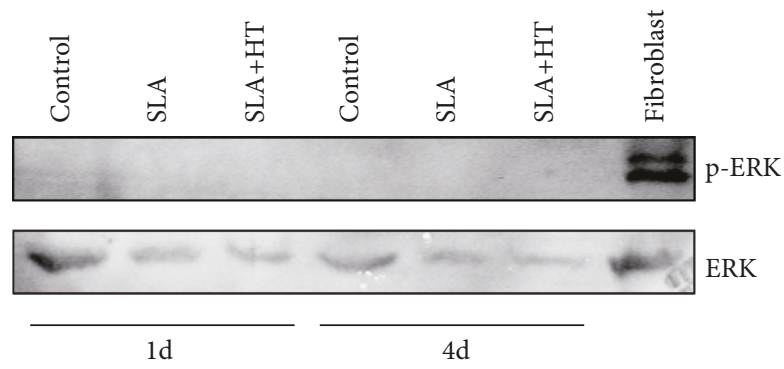

(c)

FIGURE 8: Activation of MAPK signaling pathway of osteoblasts after incubation on Ti materials with different surface modification for $1 \mathrm{~d}$ and $4 \mathrm{~d}$. (a) Western blotting analysis of the p38 phosphorylation on Ti materials with different surface modification. Increased p38 phosphorylation with the incubation time and significantly increased p38 phosphorylation could be found on Ti with SLA + HT treatment compared to control and SLA treatment. (b) Quantification of the p38 phosphorylation on day 4. (c) Western blotting of ERK phosphorylation on Ti materials with different surface modification. No ERK phosphorylation was detected from osteoblasts grown on $\mathrm{Ti}$ materials with different treatment. Same amount of protein was also extracted from fibroblasts as positive controls. Control: polished $\mathrm{Ti}$; SLA: $400 \mu \mathrm{m} \mathrm{SiO} 2$ sandblast + acid etching; SLA + HT: $400 \mu \mathrm{m} \mathrm{SiO}_{2}$ sandblast + acid etching $+4 \mathrm{~mol} / \mathrm{L} \mathrm{NaOH}$ hydrothermal for 4 h. ${ }^{*} p<0.05$.

submicroscale and nanoscale porous structures in SLA + HTtreated $\mathrm{Ti}$ samples has no effects on cell proliferation, increased effects on cell adhesion and spreading, and increased effects on cell differentiation. In addition, we confirmed that MAPKp38 signaling was involved in the osteoblast behavior on the SLA + HT-treated Ti surface.

Although the durability of Ti implants has been already proven in the biomedical field, slow as well as poor boneimplant interface is still a big challenge. To resolve this issue, various surface modifications using physical and chemical methods and coating with bioactive material were used to promote early osseointegration and fixation [21, 22]. Surface modification by physical treatment such as girt-blasting and machining improved the biomechanical fixation between implant and human body [23]. Bioactive surfaces were achieved by chemical treatment with acid/ alkali solution. In particular, sodium titanate subjected to soaking in simulated body fluid (SBF) solution and subsequent heat treatment formed bone-like apatite layer [24]. Indeed, it is known that surface roughness and hydrophilicity are two important factors that affect osteoblast behavior [12]. Here, we modified SLA surfaces via immersing in $20 \mathrm{~mL}$ of $5 \mathrm{M} \mathrm{NaOH}$ aqueous solution and hydrothermal treatment at $80^{\circ} \mathrm{C}$ for $4 \mathrm{~h}$ or $8 \mathrm{~h}$ with smaller contact angles and higher surface energies have been suggested to enhance osteogenic properties when compared with SLA surfaces, and these results were consistent with previous theories. Lai et al. have indicated that cell attachment is greater on surfaces with a higher surface energy [14]. Osteoclasts are formed via monocyte fusion, so monocytes are essential for osteoclast differentiation. According to the study conducted by Klein et al., the cell growth environment surrounding a modified SLA surface results in the limited monocyte adhesion to modified SLA surface. Moreover, the surface properties of modified SLA were found to inhibit osteoclast growth and differentiation [25]. On the other hand, higher surface free energy (SFE) on modified SLA surfaces is thought to enhance hydrophilicity, and this increased hydrophilicity and SFE of $\mathrm{Ti}$ implant surfaces may in turn accelerate the initial healing at the biomaterial/biosystem interface [26].

Furthermore, hydrothermal treatment is able to diminish metal ion release and has been employed for improving the in vitro biocompatibility and bone formation on Ti implants. By using hydrothermal treatment, Zuldesmi et al. proved that higher osteoconductivity up to RB-I $=50 \%$ in cortical bone part (about four times higher than polished $\mathrm{Ti}$ ) could be generated [17]. Most recently, Goriainov et al. found that nanowire 300 topographies (a novel nanotextured form of $\mathrm{Ti}$ ) triggered upregulation of bone-specific gene expression and 
extracellular matrix protein (OPN and collagen type I) synthesis in vitro. Early topography-induced terminal lineagespecific differentiation of SSCs resulted in minimal cell proliferation and attainment of mature distinctive tear-shaped cell morphology by day 14 of in vitro culture on nanowires 300. This enhanced osteogenic activity in vitro was coupled with the demonstration of significant enhancement of de novo contact osteogenesis at nanowire surface/bone interface within the in vivo rat calvarial model as revealed by CT analysis [27].

Cell adhesion to a substratum is one of the initial biological events, and the integrin binding to extracelluar matrix components involved in cell adhesion process can activate signaling pathways that regulate the subsequent cell behaviors including proliferation and differentiation [28]. One such pathway that may be activated and may regulate the proliferation and differentiation of osteoblasts is ERK1/2, a member of the mitogen-activated protein kinase (MAPK) pathway $[29,30]$. Studies have shown that integrin-mediated activation of ERK1/2 pathway is responsible for regulating osteoblast differentiation through modulating transcription factors in the nucleus, including Runx2 (runt-related protein 2) and OSX (osterix), downstream of Runx2 [31, 32]. However, the regulatory effect of ERK1/2 pathway on osteogenic differentiation was controversial based on the opposite results found in previous studies [31, 33, 34]. Here, we did not observe expression level change of ERK1/2 in osteoblasts grown on the Ti surface. p38 MAPK is a key player in the inflammatory responses and is involved in stress-induced gene expression [35]. Recently, Neacsu et al. found that p38 MAPK was involved in the mechanism by which Ti nanotopography attenuates the inflammatory activity of macrophages [36]. Here, we found increased p38 phosphorylation with incubation time, and significantly increased p38 phosphorylation could be found on Ti with SLA + HT treatment compared to control and SLA treatment, and we concluded that p38 served as the mechanism of osteoblast differentiation on the Ti surface.

In conclusion, we prepared the SLA + HT-treated $\mathrm{Ti}$ materials and our results demonstrated that sandblast, acid etching, and hydrothermal treatment on Ti could regulate osteoblast differentiation, while activation of the MAPK p38 signaling pathway served as the mechanism.

\section{Data Availability}

If related data are needed, please contact the corresponding author.

\section{Conflicts of Interest}

The authors declare that there is no conflict of interest regarding the publication of this paper.

\section{Acknowledgments}

This work was supported by the National Natural Science Foundation of China (81702673).

\section{References}

[1] B. de Rezende Marins, S. E. Pramiu, M. C. A. Busato, L. C. Marchi, and A. Y. Togashi, "Peri-implant evaluation of osseointegrated implants subjected to orthodontic forces: results after three years of functional loading," Dental Press Journal of Orthodontics, vol. 21, no. 2, pp. 73-80, 2016.

[2] S. A. Paul, A. K. Karthik, R. Chacko, and W. Karunya, "Audit on titanium reconstruction of mandibular defects for jaw lesions," Journal of Pharmacy \& Bioallied Sciences, vol. 6, no. 5, pp. S39-S43, 2014.

[3] F. Zhang, G. L. Yang, F. M. He, L. J. Zhang, and S. F. Zhao, "Cell response of titanium implant with a roughened surface containing titanium hydride: an in vitro study," Journal of Oral and Maxillofacial Surgery, vol. 68, no. 5, pp. 1131-1139, 2010.

[4] R. L. Sammons, N. Lumbikanonda, M. Gross, and P. Cantzler, "Comparison of osteoblast spreading on microstructured dental implant surfaces and cell behaviour in an explant model of osseointegration: a scanning electron microscopic study," Clinical Oral Implants Research, vol. 16, no. 6, pp. 657-666, 2005.

[5] K. Grandfield, S. Gustafsson, and A. Palmquist, "Where bone meets implant: the characterization of nano-osseointegration," Nanoscale, vol. 5, no. 10, pp. 4302-4308, 2013.

[6] F. A. Shah, X. Wang, P. Thomsen, K. Grandfield, and A. Palmquist, "High-resolution visualization of the osteocyte lacuno-canalicular network juxtaposed to the surface of nanotextured titanium implants in human," ACS Biomaterials Science \& Engineering, vol. 1, no. 5, pp. 305-313, 2015.

[7] L. J. Li, S. N. Kim, and S. A. Cho, "Comparison of alkaline phosphatase activity of MC3T3-E1 cells cultured on different Ti surfaces: modified sandblasted with large grit and acidetched (MSLA), laser-treated, and laser and acid-treated Ti surfaces," The Journal of Advanced Prosthodontics, vol. 8, no. 3, pp. 235-240, 2016.

[8] M. Wieland, M. Textor, N. D. Spencer, and D. M. Brunette, "Wavelength-dependent roughness: a quantitative approach to characterizing the topography of rough titanium surfaces," The International Journal of Oral \& Maxillofacial Implants, vol. 16, no. 2, pp. 163-181, 2001.

[9] B. D. Boyan, S. Lossdörfer, L. Wang et al., "Osteoblasts generate an osteogenic microenvironment when grown on surfaces with rough microtopographies," European Cells and Materials, vol. 6, pp. 22-27, 2003.

[10] O. Zinger, G. Zhao, Z. Schwartz et al., "Differential regulation of osteoblasts by substrate microstructural features," Biomaterials, vol. 26, no. 14, pp. 1837-1847, 2005.

[11] D. L. Cochran, D. Buser, C. M. Ten Bruggenkate et al., "The use of reduced healing times on ITI $^{\circledR}$ implants with a sandblasted and acid-etched (SLA) surface: early results from clinical trials on ITI $^{\circledR}$ SLA implants," Clinical Oral Implants Research, vol. 13, no. 2, pp. 144-153, 2002.

[12] M. A. Alfarsi, S. M. Hamlet, and S. Ivanovski, "Titanium surface hydrophilicity modulates the human macrophage inflammatory cytokine response," Journal of Biomedical Materials Research Part A, vol. 102, no. 1, pp. 60-67, 2014.

[13] Y. X. Gu, J. Du, M. S. Si, J. J. Mo, S. C. Qiao, and H. C. Lai, “The roles of PI3K/Akt signaling pathway in regulating MC3T3-E1 preosteoblast proliferation and differentiation on SLA and SLActive titanium surfaces," Journal of Biomedical Materials Research Part A, vol. 101, no. 3, pp. 748-754, 2013.

[14] H. C. Lai, L. F. Zhuang, X. Liu, M. Wieland, Z. Y. Zhang, and Z. Y. Zhang, "The influence of surface energy on early 
adherent events of osteoblast on titanium substrates," Journal of Biomedical Materials Research Part A, vol. 93, no. 1, pp. 289-296, 2010.

[15] S. M. Bang, H. J. Moon, Y. D. Kwon, J. Y. Yoo, A. Pae, and I. K. Kwon, "Osteoblastic and osteoclastic differentiation on SLA and hydrophilic modified SLA titanium surfaces," Clinical Oral Implants Research, vol. 25, no. 7, pp. 831-837, 2014.

[16] K. Hamada, M. Kon, T. Hanawa, K.' Yokoyama, Y. Miyamoto, and K. Asaoka, "Hydrothermal modification of titanium surface in calcium solutions," Biomaterials, vol. 23 , no. 10, pp. 2265-2272, 2002.

[17] M. Zuldesmi, A. Waki, K. Kuroda, and M. Okido, "High osteoconductive surface of pure titanium by hydrothermal treatment," Journal of Biomaterials and Nanobiotechnology, vol. 4, no. 3, pp. 284-290, 2013.

[18] K. J. Livak and T. D. Schmittgen, "Analysis of relative gene expression data using real-time quantitative PCR and the $2^{-\Delta \Delta C}$ method," Methods, vol. 25, no. 4, pp. 402-408, 2001.

[19] A. Civantos, E. Martínez-Campos, V. Ramos, C. Elvira, A. Gallardo, and A. Abarrategi, "Titanium coatings and surface modifications: toward clinically useful bioactive implants," ACS Biomaterials Science \& Engineering, vol. 3, no. 7, pp. 1245-1261, 2017.

[20] D. L. Cochran, J. M. Jackson, J. P. Bernard et al., “A 5-year prospective multicenter study of early loaded titanium implants with a sandblasted and acid-etched surface," International Journal of Oral \& Maxillofacial Implants, vol. 26, no. 6, pp. 1324-1332, 2011.

[21] J. Y. Suh, O. C. Jeung, B. J. Choi, and J. W. Park, "Effects of a novel calcium titanate coating on the osseointegration of blasted endosseous implants in rabbit tibiae," Clinical Oral Implants Research, vol. 18, no. 3, pp. 362-369, 2007.

[22] H. C. Hsu, S. C. Wu, S. K. Hsu, Y. H. Liao, and W. F. Ho, "Effect of different post-treatments on the bioactivity of alkali-treated Ti-5Si alloy," Bio-Medical Materials and Engineering, vol. 28, no. 5, pp. 503-514, 2017.

[23] L. Le Guehennec, A. Soueidan, P. Layrolle, and Y. Amouriq, "Surface treatments of titanium dental implants for rapid osseointegration," Dental Materials, vol. 23, no. 7, pp. 844854, 2007.

[24] T. Kokubo and S. Yamaguchi, "Novel bioactive titanate layers formed on Ti metal and its alloys by chemical treatments," Materials, vol. 3, no. 1, pp. 48-63, 2010.

[25] M. O. Klein, A. Bijelic, T. Ziebart et al., "Submicron scalestructured hydrophilic titanium surfaces promote early osteogenic gene response for cell adhesion and cell differentiation," Clinical Implant Dentistry and Related Research, vol. 15, no. 2, pp. 166-175, 2013.

[26] H. Xing, X. Wang, S. Xiao et al., “Osseointegration of layer-bylayer polyelectrolyte multilayers loaded with IGF1 and coated on titanium implant under osteoporotic condition," International Journal of Nanomedicine, vol. 12, pp. 7709-7720, 2017.

[27] V. Goriainov, G. Hulsart-Billstrom, T. Sjostrom, D. G. Dunlop, B. Su, and R. O. C. Oreffo, "Harnessing nanotopography to enhance osseointegration of clinical orthopedic titanium implants-an in vitro and in vivo analysis," Frontiers in Bioengineering and Biotechnology, vol. 6, p. 44, 2018.

[28] K. Anselme, "Osteoblast adhesion on biomaterials," Biomaterials, vol. 21, no. 7, pp. 667-681, 2000.

[29] M. Katz, I. Amit, and Y. Yarden, "Regulation of MAPKs by growth factors and receptor tyrosine kinases," Biochimica et
Biophysica Acta (BBA) - Molecular Cell Research, vol. 1773, no. 8, pp. 1161-1176, 2007.

[30] X. Liu, W. Si, X. Liu et al., "JMJD6 promotes melanoma carcinogenesis through regulation of the alternative splicing of PAK1, a key MAPK signaling component," Molecular Cancer, vol. 16, no. 1, p. 175, 2017.

[31] L. F. Zhuang, H. H. Jiang, S. C. Qiao et al., "The roles of extracellular signal-regulated kinase $1 / 2$ pathway in regulating osteogenic differentiation of murine preosteoblasts MC3T3-E1 cells on roughened titanium surfaces," Journal of Biomedical Materials Research Part A, vol. 100, no. 1, pp. 125-133, 2012.

[32] K. G. Neoh, X. Hu, D. Zheng, and E. T. Kang, "Balancing osteoblast functions and bacterial adhesion on functionalized titanium surfaces," Biomaterials, vol. 33, no. 10, pp. $2813-$ $2822,2012$.

[33] S. J. Kono, Y. Oshima, K. Hoshi et al., "Erk pathways negatively regulate matrix mineralization,” Bone, vol. 40, no. 1, pp. 68-74, 2007.

[34] R. K. Jaiswal, N. Jaiswal, S. P. Bruder, G. Mbalaviele, D. R. Marshak, and M. F. Pittenger, "Adult human mesenchymal stem cell differentiation to the osteogenic or adipogenic lineage is regulated by mitogen-activated protein kinase," The Journal of Biological Chemistry, vol. 275, no. 13, pp. 9645-9652, 2000.

[35] Y. Yang, S. C. Kim, T. Yu et al., "Functional roles of p38 mitogen-activated protein kinase in macrophage-mediated inflammatory responses," Mediators of Inflammation, vol. 2014, Article ID 352371, 13 pages, 2014.

[36] P. Neacsu, A. Mazare, P. Schmuki, and A. Cimpean, "Attenuation of the macrophage inflammatory activity by $\mathrm{TiO}_{2}$ nanotubes via inhibition of MAPK and NF- $\kappa$ B pathways," International Journal of Nanomedicine, vol. 10, pp. 64556467, 2015. 


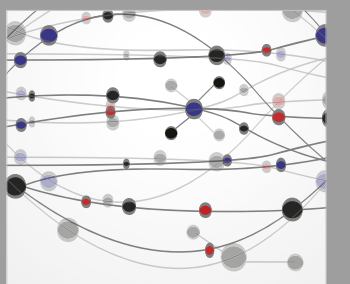

The Scientific World Journal
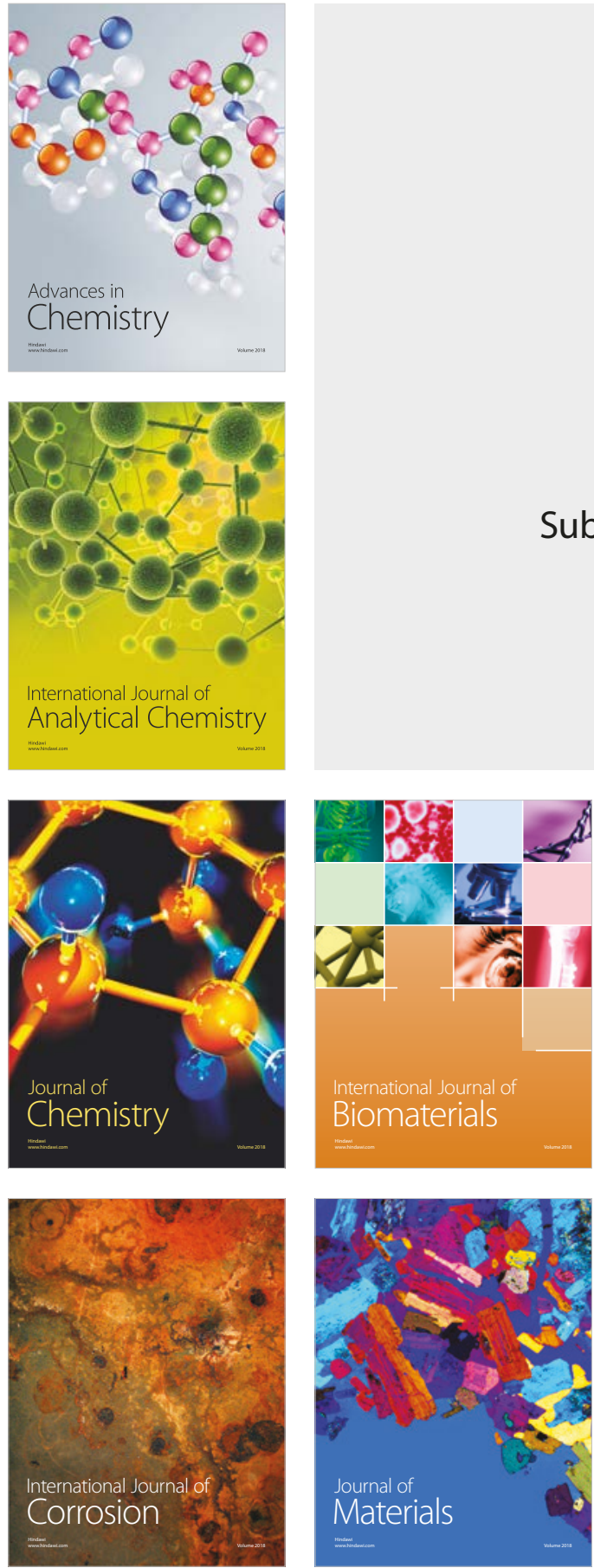

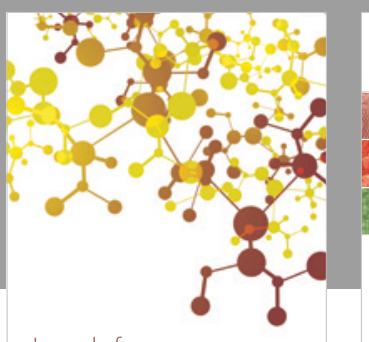

Journal of

Applied Chemistry
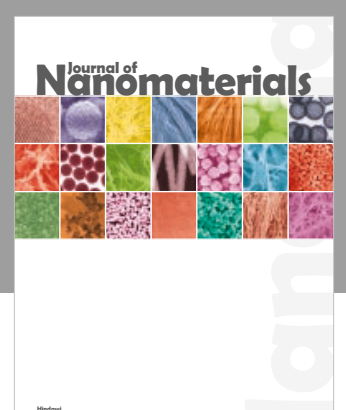

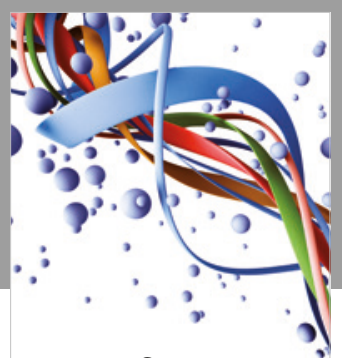

Scientifica

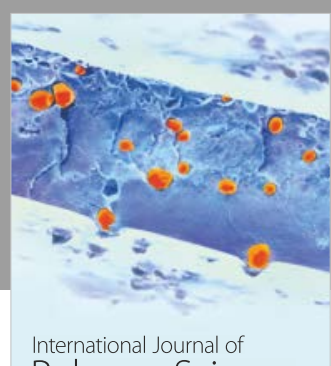

Polymer Science

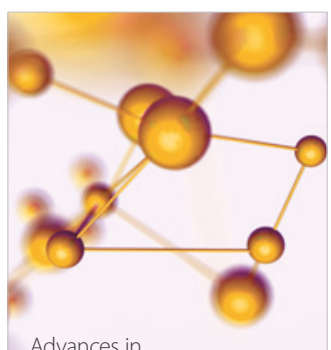

Physical Chemistry
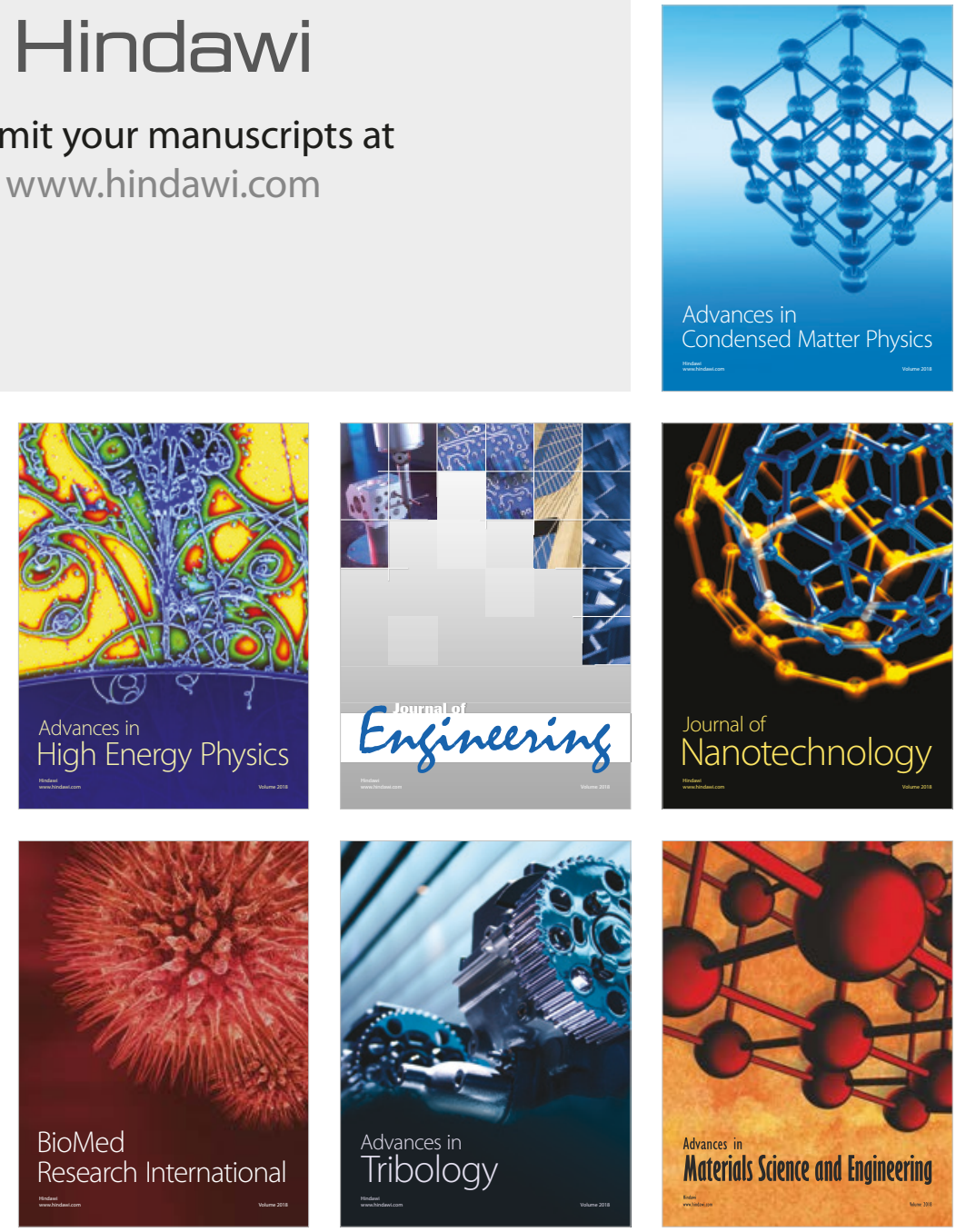